\title{
Perancangan dan Analisis Karakteristik Traksi Pada Mobil Pedesaan Serbaguna WAPRODES
}

\author{
Radian Fauzia Rahman, Alief Wikarta, dan I Nyoman Sutantra \\ Departemen Teknik Mesin, Fakultas Teknologi Industri, \\ Institut Teknologi Sepuluh Nopember (ITS) \\ e-mail:wikarta@me.its.ac.id, radianfauzia@gmail.com
}

\begin{abstract}
Abstrak-Mobil WAPRODES merupakan mobil serbaguna karena mempunyai tiga fungsi yaitu untuk memuat barang dengan kapasitas maksimal $1500 \mathrm{Kg}$, menggerakan alat pertanian, serta dapat memuat delapan orang. Mobil ini merupakan gabungan dari kendaraan Grandong yang mempunyai fungsi menggerakkan alat produksi pertanian serta mobil pick up yang mempunyai fungsi sebagai pengangkut barang. Perhitungan dalam penelitian ini yaitu pemilihan engine, pemilihan rasio transmisi mengunakan progresi geometris, perhitungan aliran daya, perhitungan prediksi performa kendaraan, pemilihan penggerak $2 \mathrm{WD}$ dan $4 \mathrm{WD}$ serta analisis slip. Hasil yang didapatkan pada tugas akhir ini adalah pada saat menempuh medan tanjakan maksimal dan kecepatan maksimal yang diinginkan maka rasio transmisi yang digunakan berturut-turut 5.66, 3.05, 1.65, dan 0.89 untuk rasio gigi 1 sampai 4, sedangkan untuk penggerak terakhir digunakan rasio bernilai 4.8. Dengan rasio tersebut mobil multiguna pedesaan memiliki kemampuan menanjak maksimal yaitu $47 \%$ dan akselerasi maksimal $3 \mathrm{~m} / \mathrm{s}^{2}$. Penggunaan modifikasi sistem transfer case dapat mengintegrasikan antara mode produksi, 2WD, 4WD. Untuk 2WD menggunakan penggerak roda belakang dapat menghasilkan $7957 \mathrm{~N}$ ketika kendaraan pada jalan datar. Pada 4WD dilakukan pembagian torsi dengan porsi $45 \%$ untuk roda belakang menghasilkan traksi sebesar $3200 \mathrm{~N}$ dan $55 \%$ untuk penggerak belakang yang dapat menghasilkan traksi $3800 \mathrm{~N}$.
\end{abstract}

Kata Kunci-Karakteristik Traksi, Pemilihan rasio, Penyesuaian Karakter Mesin dan Transmisi, WAPRODES.

\section{PENDAHULUAN}

$\mathrm{P}$ ERKEMBANGAN alat transportasi sekarang ini sudah sangat pesat. Salah satu kendaraan tersebut adalah mobil serbaguna yang bermanfaat bagi masyarakat pedesaan agar menunjang kegiatan proses pertanian dan perikanan. Kondisi demikian membuat mobil pedesaan Grandong yang telah ada tidak cukup hanya sebagai mobil yang dapat mengangkut sekaligus mengolah hasil pertanian, tetapi mobil lebih sempurna jika dirancang dapat melewati medan sulit secara optimal.

Daerah operasi mobil pada daerah pedesaan membuat faktor kebutuhan kecepatan yang diinginkan berbeda dengan mobil penumpang pada umumnya. Kendaraan yang dirancang untuk kebutuhan komersial seperti truk biasanya memiliki kecepatan maksimal yang rendah berkis ar antara 70 - $80 \mathrm{~km} / \mathrm{jam}$. Mobil yang dirancang pada tugas akhir ini ditentukan jika kecepatan maksimal yang dapat dibentuk hanya sebesar $90 \mathrm{~km} / \mathrm{jam}$ saja, hal tersebut berkaitan dengan laju maksimum dengan jalan yang dapat dilewati di pedesaan yang bervariasi.

Dalam penelitian ini diperlukan sebuah pemilihan mesin yang cocok untuk kendaraan ini dengan harga yang murah, dan juga desain dan analisis sistem powertrain dari mulai engine hingga rasio transmisi yang diharapkan agar kendaraan dapat mengatasi hambatan dengan baik sehingga efektifitas kendaraan untuk melalui jalan yang bermacam macam dapat dilalui dengan baik.

\section{URAIAN PENELITIAN}

Pada penelitian ini dibutuhkan traksi kendaraan yang dapat menggerakan kendaraan dengan kecepatan konstan pada kecepatan $90 \mathrm{~km} / \mathrm{h}$, traksi tersebut didapatkan dari hasil perhitungan hambatan aerodinamis dan hambatan rolling. Untuk penentuan engine kendaraan maka dihitung total gaya hambat kendaraan dikali dengan kecepatan yang diinginkan. Gaya traksi didapat dari perhitungan total gaya hambat aerodinamis, gaya hambat rolling, hambatan gradien. Perhitungan rasio gigi ditentukan dengan metode progresi geometris sehingga rasio gigi tertinggi didapatkan dari gaya yang diperlukan menggerakan kendaraan dari posisi diam hingga bergerak, serta gaya hambat kendaraan ketika kecepatan rendah yaitu inersia kendaraan, dan hambatan rolling. Untuk rasio gigi terendah didapatkan dari pertimbangan kendaraan dapat mencapai kecepatan maksimum sehingga hambatan yang dilawan hanya hambatan aerodinamis dan hambatan rolling. Grafik traksi kendaraan didapat dari data engine digabung dengan rasio gigi lalu dibandingkan pada setiap kecepatan sehingga menghasilkan data daya traksi yang mampu dihasilkan oleh seluruh sistem powertrain. Diagram traksi dapat diperoleh menggabungkan semua data diatas, lalu untuk memperjelas analisa karakteristik traksi juga dibuat diagram performa kendaraan serta kemampuan menanjak dan kemampuan akselerasi serta grafik batas adhesisaat mobil berjalan dalam mode 2WD dan 4WD untuk menganalisa pengaruh perubahan mode berkendara pada performa kendaraan. Setelah didapatkan grafik traksi maka diteruskan dengan mengitung prediksi kinerja kendaraan agar dapat mengetahui percepatan, kemampuan menanjak, serta kecepatan maksimum kendaraan. Untuk pemilihan antara penggerak roda depan (FWD) dan penggerak roda belakang (RWD) maka penggerak 2WD yang terbaik diseleksi dari analis is slip serta kemampuan maksimum kendaraan melalui hambatan tanjak. Pemilihan komposisi traksi yang terbaik untuk dialirkan menuju roda depan dan roda belakang pada 4WD diperlukan analisis slip dan kemampuan maksimum mengahadapi hambatan tanjak.

\section{A. Power yang Dibutuhkan Kendaraan}

Menentukan gaya traksi yang dibutuhkan kendaraan pada saat kecepatan tertentu dengan menggunakan rumus berikut,

$$
F_{t \text { max }}=f_{r} \cdot W+\frac{1}{2} \rho \cdot C_{D} \cdot A_{f} \cdot V^{2} \max
$$


Setelah didapatkan gaya traksi kendaraan maka untuk mencari power kendaraan yang cocok untuk kendaraan sebagaiberikut,

$$
P_{\max }=F_{t \max } \cdot V_{\max }
$$

\section{B. Gaya Hambat Kendaraan}

Gaya hambat yang terjadi pada kendaraan antara lain hambatan aerodinamis, hambatan rolling, dan hambatan tanjak. Untuk hambatan aerodinamis [1] dapat dijabarkan dalam rumus sebagaiberikut,

$$
R_{a}=\frac{1}{2} \times \rho \times \mathrm{C}_{\mathrm{d}} \times \mathrm{A}_{\mathrm{f}} \times \mathrm{V}_{\mathrm{a}}^{2}
$$

Untuk rumus mencari hambatan rolling [2] sebagai berikut,

$$
R_{r}=f_{r} x W_{\text {total }}
$$

Hambatan tanjak didapat dari rumus berikut,

$$
\mathrm{R}_{\mathrm{g}}=\mathrm{W}_{\text {total }} \sin \theta=\text { hambatan tanjakan }(\mathrm{N})
$$

\section{Penentuan Rasio Gigi}

Dalam menentukan rasio gigi [3] maka diperlukan analisis terhadap kebutuhan kendaraan, untuk menghitung rasio gigi pertama digunakan rumus,

$$
i_{1}=\frac{\left(\frac{W}{g} \cdot a+R_{r}\right) \cdot r}{M_{e} \cdot i_{d} \cdot \eta_{t}}
$$

Sedangkan untuk rasio gigi terendah digunakan rumus sebagaiberikut,

$$
i_{4}=\frac{\left(R_{a}+R_{r}\right) \cdot r}{M_{e} \cdot i_{d} \cdot \eta_{t}}
$$

Jika rasio tingkat gigi pertama dan rasio gigi tingkat terakhir telah diperoleh, hal yang perlu dicari yaitu mencari konstanta perbandingan rasio gigi akhir dan pertama. Untuk menentukan rasio gigi $\left(\mathrm{K}_{\mathrm{g}}\right)$ maka dihitung dengan rumus,

$$
K_{g}=\left(\frac{i_{n}}{i_{1}}\right)^{\frac{1}{n-1}}
$$

Menentukan rasio gigi kedua dan rasio gigi ketiga sebagai berikut,

$$
\begin{aligned}
& i_{2}=\mathrm{i} 1 \times \mathrm{Kg} \\
& i_{3}=\mathrm{i} 2 \times \mathrm{Kg}
\end{aligned}
$$

\section{Penetuan traksi kendaraan}

Pada perhitungan traksi [4] ini maka halyang perlu dihitung yaitu traksi kendaraan dan hambatan kendaraan setiap kondisi tingkat gigi kendaraan. Dalam perhitungan gaya traksi kendaraan diselesaikan dengan persamaan yaitu,

$$
F_{t}=\frac{i_{t} \cdot i_{g} \cdot M_{e}}{r} \eta_{t}
$$

untuk menghitung kecepatan kendaraan maka,

$$
V_{k}=\frac{3.6 \pi \cdot r \cdot N_{e}}{30 \cdot i_{t} \cdot i_{g}}
$$

dan untukmenghitung traksi ideal kendaraan maka,

$$
F=\frac{P}{V a}
$$

\section{E. Prediksikinerja kendaraan}

Untuk mengitung kemampuan sudut tanjak maksimum [5] kendaraan menggunakan persamaan berikut,

$$
\theta_{v}=\arcsin \left(\frac{F_{t}-R_{r}-R_{a}}{W}\right)
$$

Menghitung percepatan maksimum [5] digunakan rumus berikut,

$$
a_{v}=\frac{F_{t}-R_{r}-R_{a}}{\lambda \cdot m}
$$

\section{F. Batas adhesi pada 2 WD}

Pada perhitungan gaya kontak 2WD [6][7] dapat diselesaikan dengan persamaan berikut,

$$
F_{f}=\mu . \mathrm{W}
$$

Untuk berat kendaraan yang digunakan pada penggerak depan sebagai berikut,

$$
W_{f}=\frac{W \cdot l_{2} \cdot \cos \theta-R_{a} \cdot h_{a}-h \cdot a \frac{w}{g} \pm W \cdot h \cdot \sin \theta}{L}
$$

Untuk berat kendaraan pada penggerak belakang sebagai berikut,

\begin{tabular}{|c|c|}
\hline Wheel base & $2200 \mathrm{~mm}$ \\
\hline Length & $3200 \mathrm{~mm}$ \\
\hline Width & $1477 \mathrm{~mm}$ \\
\hline High & $1765 \mathrm{~mm}$ \\
\hline Ground clearance & $200 \mathrm{~mm}$ \\
\hline Load capacity & $900 \mathrm{~kg}$ \\
\hline Vehicle weight & $600 \mathrm{~kg}$ \\
\hline Body & $\begin{array}{l}\text { Stell frame with steel plate and adjustable } \\
\text { seat }\end{array}$ \\
\hline System & Portable assembly with 3 mode \\
\hline Mode & Load, Passanger, and Production \\
\hline Passanger Capacity & 6 person \\
\hline Production Device & 3 machine up to $20 \mathrm{HP}$ \\
\hline Output & $20 \mathrm{HP} / 3000 \mathrm{rpm}$ \\
\hline Dry Weight & $93 \mathrm{~kg}$ \\
\hline Drag coefficient & 0.6 \\
\hline Frontal area & $2 \mathrm{~m}^{2}$ \\
\hline \multicolumn{2}{|c|}{$\begin{array}{l}\text { Gambar } 2 \text {. Spesifikasi kendaraan W APRODES. } \\
\text { Dari spesifikasi diketahui bahwa mesin yang digunak }\end{array}$} \\
\hline \multicolumn{2}{|c|}{$\begin{array}{l}\text { Dari spesifikasi diketahui bahwa mesin yang digunakan } \\
\text { pada penelitian sebelumnya hanya } 1000 \mathrm{cc} \text { sehingga kurang } \\
\text { maksimal untuk melawan hambatan kendaraan. }\end{array}$} \\
\hline
\end{tabular}

$$
W_{r}=\frac{W \cdot l_{2} \cdot \cos \theta+R_{a} \cdot h_{a}+h \cdot a \frac{w}{g} \pm W \cdot h \cdot \sin \theta}{L}
$$

\section{G. Batas adhesi pada $4 W D$}

Batas adhesi yang terjadi pada kendaraan dengan penggerak 4WD [7] menggunakan rumus gaya gesek sebagai berikut,

$$
F f=\mu \cdot W_{f}
$$

\section{H. Konsep Rancangan}

Konsep rancangan yang telah ada dari hasil penelitian sebelumnya [7][8] yaitu sebagaiberikut.

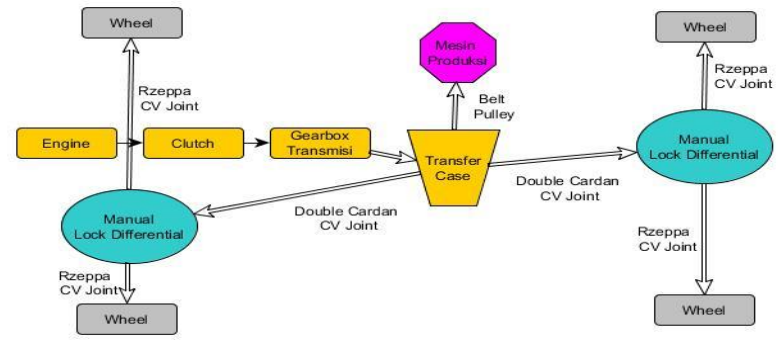

Gambar 1. Skema Mobil Produksi Pedesaan 4WDdengan modifikasi TransferCase.

\section{Spesifikasi Kendaraan}

Spesifikasi kendaraan dapat dilihat pada tabel berikut,

\section{HASIL DAN PEMBAHASAN}

\section{A. Pemilihan Mesin}

Pemilihan mesin dilakukan setelah diketahui hasil perhitungan dari rumus (1) dan (2), sehingga didapatkan power yang digunakan untuk menggerakan kendaraan ketika $90 \mathrm{~km} / \mathrm{h}$ adalah 14,4 KW. Lalu dilakukan pembobotan untuk pemilihan mesin seperti pada tabel 1.

Dari hasil pembobotan pada tabel 1 didapatkan bahwa ketiga mesin tersebut diberikan nilai dengan parameter yang telah ditentukan. Angka yang menunjukkan nilai sebuah parameter. Setelah semua parameter diberikan nilai pada 
masing masing maka jumlah nilai yang didapatkan tertinggi yaitu RATNA DDi 2700F seperti pada gambar 3 dengan nilai 21, kedua yaitu KUBOTA D1105-E4B dengan nilai 19, serta yang terakhir adalah YANMAR TS $230 \mathrm{H}$ - di dengan nilai 17.

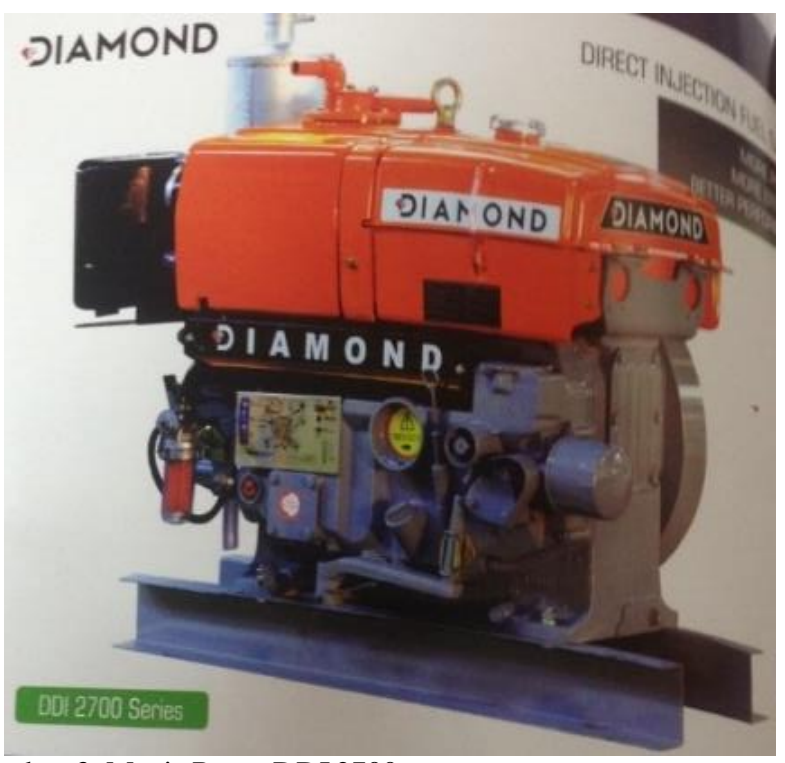

Gambar 3. Mesin Ratna DDI 2700.

Tabel 1.

Pemilihan mesin

\begin{tabular}{|r|l|r|r|r|r|r|r|}
\hline \multirow{2}{*}{ No } & \multirow{2}{*}{ Kategori } & \multicolumn{4}{|c|}{ Spesifikasi } & \multicolumn{3}{|c|}{ Nilai } \\
\hline $\mathbf{1}$ & Harga & $42 \mathrm{Juta}$ & $29 \mathrm{Juta}$ & $28 \mathrm{Juta}$ & 1 & 3 & 3 \\
\hline $\mathbf{2}$ & Power & $18.5 \mathrm{KW}$ & $20.13 \mathrm{KW}$ & $17,2 \mathrm{KW}$ & 2 & 3 & 2 \\
\hline $\mathbf{3}$ & Torsi & $73 \mathrm{~N} \cdot \mathrm{m}$ & $88 \mathrm{~N} \cdot \mathrm{m}$ & $70 \mathrm{~N} \cdot \mathrm{m}$ & 2 & 3 & 1 \\
\hline $\mathbf{4}$ & RPM & 3000 & 2400 & 2200 & 3 & 2 & 2 \\
\hline $\mathbf{5}$ & Spare part & Ready .Ind & Ready .Ind & Ready .Ind & 3 & 3 & 3 \\
\hline $\mathbf{6}$ & Berat bersih & $93 \mathrm{Kg}$ & $198 \mathrm{~kg}$ & $205 \mathrm{Kg}$ & 3 & 2 & 1 \\
\hline $\mathbf{7}$ & Made in & Jepang & Indonesia & Jepang & 3 & 2 & 3 \\
\hline $\mathbf{8}$ & Displacement & $1150 \mathrm{cc}$ & $1250 \mathrm{cc}$ & $1132 \mathrm{cc}$ & 2 & 3 & 2 \\
\hline & & Jumlah & & & 19 & 21 & 17 \\
\hline
\end{tabular}

TRAKSI DIBUTUHKAN, F (N)

(ROAD SURFACE)

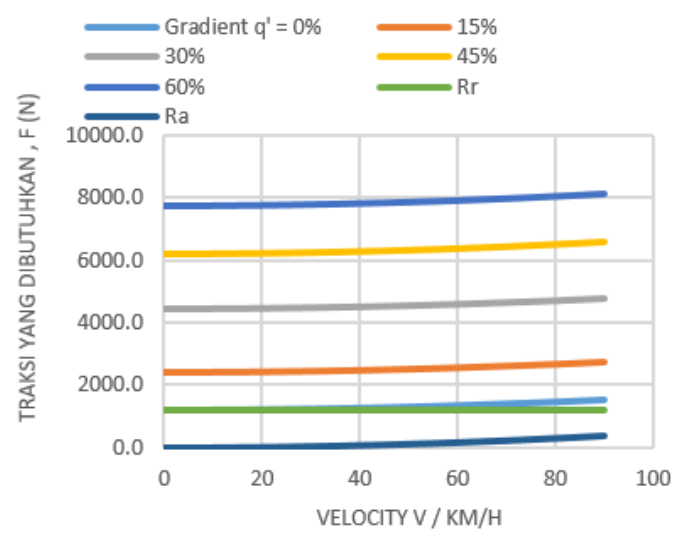

Gambar 4. Gaya hambat kendaraan.
Tabel 2 .

Perhitungan rasio gigi transmisi

\begin{tabular}{|c|c|c|c|c|c|}
\hline Rasio Gardan & Gigi 1 & Gigi 2 & Gigi 3 & Gigi 4 & Kg \\
\hline 4.8 & 5.66 & 3.05 & 1.56 & 0.89 & 0.53 \\
\hline
\end{tabular}

\section{B. Analisis Gaya Hambat}

Gaya hambat didapatkan dari rumus (3), (4), (5) sehingga setelah dihitung dapat diplot kedalam suatu grafik seperti pada gambar 4. Pada gaya hambat tersebut didapatkan bahwa hambatan tanjak mencapai $60 \%$ dengan nilai sekitar $7800 \mathrm{~N}$, sedangkan untuk hambatan rolling didapatkan nilai sekitar $500 \mathrm{~N}$ dan untuk hambatan aerodinamis didapatkan sekitar 1000 N. Semua hambatan akan berubah jika kecepatan kendaraan semakin tinggi maka semakin tinggi juga hambatannya.

\section{Penentuan Rasio Gigi}

Perhitungan rasio gigi telah dilakukan sehingga untuk lebih mudah maka disajikan dalam bentuk tabel seperti pada tabel 2.

Dari hasil perhitungan pada tabel 2 didapatkan bahwa transmisi gigi 1 sampai 4 mempunyai nilai berturut - turut yaitu $5.66,3.05,1.56,0.89$. Untuk konstanta perbandingan didapatkan 0.53 dan untuk rasio gardan berdasarkan penelitian sebelumnya didapatkan 4.8 .

\section{Traksi Kendaraan}

Perhitungan traksi dapat dihitungan dari rumus (11), (12), dan (13). Dari perhitungan didapatkan hasil sehingga untuk memudahkan analisis diperlukan sebuah grafik traksi seperti pada gambar 5.

Pada gambar 5 kendaraan dengan 4 tingkat transmisi sudah mendekati garis traksi ideal tetapi tetap tidak dapat menyerupai traksi ideal karena ada banyak faktor. Pada Tingkat gigi 1 traksi maksimum yang dapat dicapai yaitu sekitar $6800 \mathrm{~N}$ pada kecepatan sekitar $10 \mathrm{~km} / \mathrm{h}$, untuk tingkat gigi 2 traksi maksimum yang dapat dicapai yaitu sekitar 3700 $\mathrm{N}$ pada kecepatan sekitar $15 \mathrm{~km} / \mathrm{h}$, untuk tingkat gigi 3 traksi maksimum yang dapat dicapai yaitu sekitar $2000 \mathrm{~N}$ pada kecepatan sekitar $20 \mathrm{~km} / \mathrm{h}$, untuk tingkat gigi 4 traksi maksimum yang dapat dicapai yaitu sekitar $1300 \mathrm{~N}$ pada kecepatan sekitar $50 \mathrm{~km} / \mathrm{h}$. Pada gambar 4 hasil desain traksi dengan menggunakan gigi 1 dapat mengatasi maksimum tanjakan $45 \%$ dan $30 \%$, untuk gigi 2 dapat mengatasi gradien $15 \%$, dan dengan gigi 3 dan gigi 4 dapat mengatasi hambatan gradien $0 \%$, hambatan aerodinamis, dan hambatan rolling.

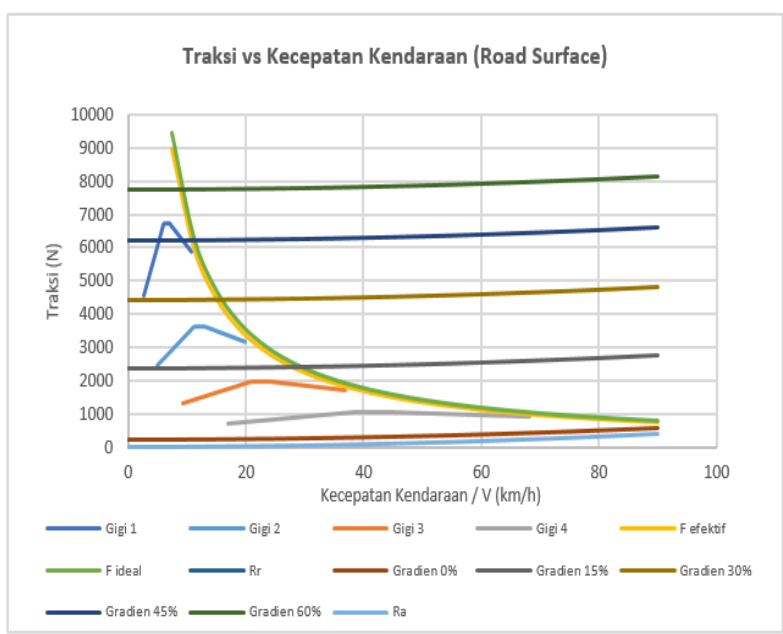

Gambar 5. Traksi kendaraan pada jalan raya. 


\section{E. Pembahasan prediksi kinerja Kendaraan}

Dalam menentukan gradability kendaraan maka persamaan yang digunakan antara lain (3), (4), (11), dan (14) dan untuk menentukan grafik performa persamaan yang digunakan yaitu (3), (4), (11), dan (15). Untuk mempermudah analisis maka dibuat sebuah grafik seperti pada gambar 5.

Pada gambar 6 dapat dilihat bahwa kemampuan menanjak pada gigi 1 dapat melewati sudut tanjak sekitar $47 \%$, tetapi dengan gigi 4 kendaraan hanya dapat melewati sudut tanjak sekitar $4 \%$ karena desain gigi 4 dibuat untuk mencapai kecepatan tertinggi bukan untuk melawan hambatan tanjak. Untuk performa akselerasi gigi 1 dapat menghasilkan percepatan sebesar $3 \mathrm{~m} / \mathrm{s}^{2}$ sedangkan dengan gigi 4 dapat menghasilkan $0,43 \mathrm{~m} / \mathrm{s}^{2}$.

\section{F. Pemilihan Mode Operasi 2 WD}

Mode operasi 2WD merupakan mode kendaraan dengan penggerak hanya dua ban saja yang berjalan, pilihan mode pun hanya ada dua yaitu penggerak roda depan dan penggerak roda belakang.

Detail pengaruh mode $2 \mathrm{WD}$ antar penggerak roda depan atau penggerak roda belakang dalam meningkatkan performa mobil dapat dilihat pada gambar 7 saat mode 2 WD penggerak ban belakang (RWD) dan penggerak roda depan (FWD). Pada FWD kontur permukaan jalan aspal dengan menggunakan gigi 1 maka kendaraan dapat mengatasi permukaan jalan kering dengan gesekan dan gradien sebesar $0 \%$ dan $45 \%$ tetapi tidak cukup untuk melawan permukaan jalan basah meski dengan gradien $45 \%$ karena dengan batas adhesi seperti itu cenderung ban depan akan terjadi slip. Untuk mengatasi slip tersebut maka digunakan gigi 2 karena batas adhesi gesek tersebut ada diatas gigi 2 sehingga kendaraan tidak mengalami slip, tetapi gigi 2 hanya mampu melewati gradien 15\% saja. Untuk FWD batas adhesi dapat dilawan hanya dengan gigi 3, hal tersebut sangat buruk karena ada dua tingkat gigi yang tidak terpakai karena ada batas adhesi.
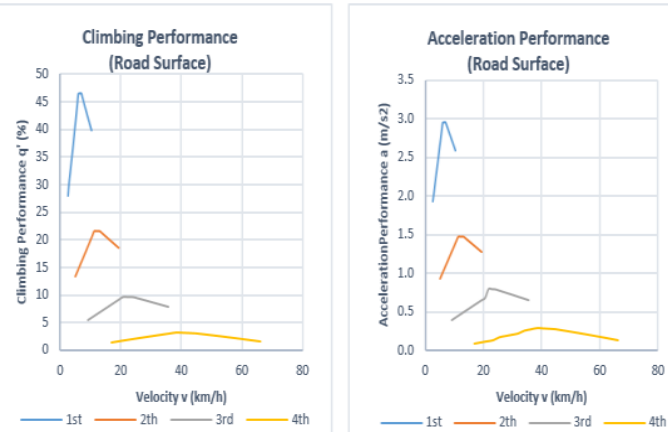

Gambar 6. Grafik prediksi performakendaraan.
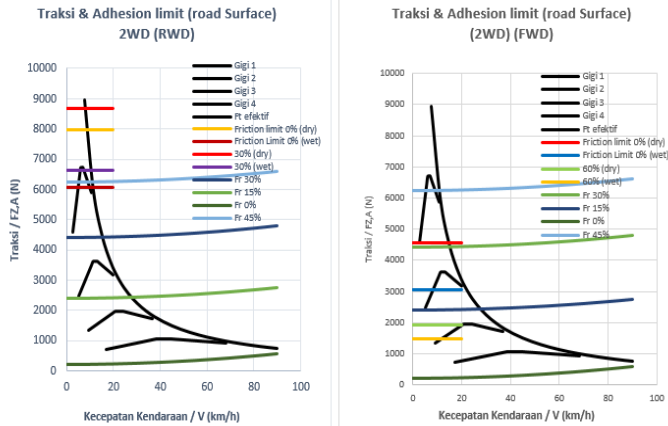

Gambar 7. Grafik Traksi dan Batas adhesi pada RWD dan FWD.
Pada tabel 3 dan tabel 4 dilakukan perbandingaan untuk setiap tingkat transmisi yang digunakan untuk tidak melewati batas adhesi dengan mode RWD dan FWD. Pada RWD penggunaan gigi sangat baik karena cukup dengan gigi 1 dan gigi 2 sudah tidak melewati mayoritas batas adhesi gesek setiap keadaan gradien yang bervariasi dari $0 \%$ - 45\% serta keadaan jalan mulai dari basah hingga kering, tetapi penggunaan gigi 1 tidak dapat digunakan hanya pada saat jalanan lumpur yang basah dengan gradien $0 \%$ - 45\%. Pada mode FWD kendaraan tidak dapat digunakan gigi 1 karena traksi terlalu besar yang mengakibatkan slip. Maka pada mode ini biasanya hanya menggunakan gigi 2 dan gigi 3 saja, tetapi pada saat kendaraan masuk melalui jalan berlumpur dengan gradien $0 \%-45 \%$ kendaraan tidak dapat melaju karena gigi 4 traksi yang dihasilkan diatas batas adhesi. Dari tabel 3 dapat ditarik kesimpulan dengan gigi 1 dapat melewati Batas adhesi dan semakin sedikit penggunaan tingkat transmisi untuk tidak melewati batas adhesi maka sangat bagus terlihat dengan RWD semua batas adhesi dapat dilawan dengan tingkat gigi 1, gigi 2 dan gigi 3, sedangkan dengan FWD batas adhesi hanya dapat dilawan dengan gigi 2, gigi 3, dan gigi 4 bahkan ada batas adhesi yang tidak dapat dilawan dengan mode FWD.

Tabel 3 .

Penggunaan transmisi pada RWD

\begin{tabular}{|c|c|c|c|c|c|c|c|c|}
\hline \multirow{2}{*}{ JALAN } & \multicolumn{5}{|c|}{ Tingkat Transmisi dengan RWD } \\
\cline { 2 - 9 } & \multicolumn{5}{|c|}{ Dry } & \multicolumn{3}{c|}{ Wet } \\
\cline { 2 - 9 } & $0 \%$ & $15 \%$ & $30 \%$ & $45 \%$ & $0 \%$ & $15 \%$ & $30 \%$ & $60 \%$ \\
\hline Jalan raya & Gigi 1 & Gigi 1 & Gigi 1 & Gigi 1 & Gigi 1 & Gigi 1 & Slip & Slip \\
\hline Jalan krikil & Gigi 2 & Slip & Slip & Slip & Gigi 2 & Slip & Slip & Slip \\
\hline Jalan Lumpur & Slip & Slip & Slip & Slip & Gigi 3 & Slip & Slip & Slip \\
\hline
\end{tabular}

Tabel 4 .

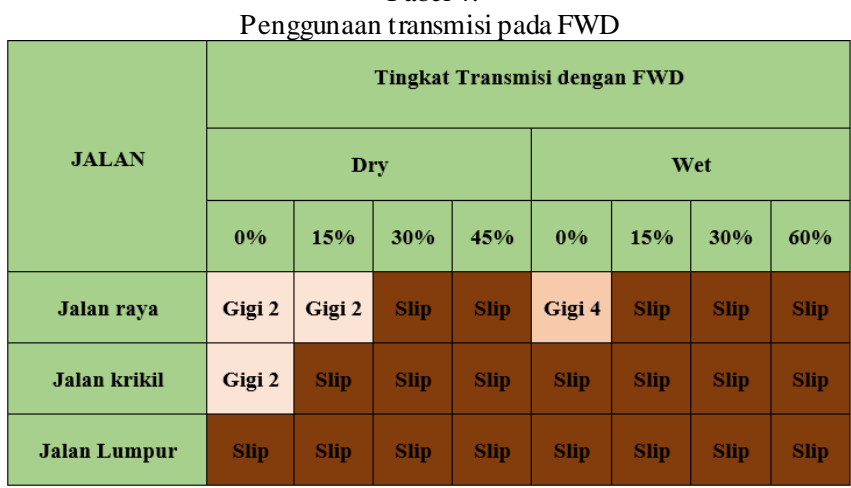

\section{G. Pemilihan Mode Operasi 4WD}

Untuk pemilihan komposisi pembagian traksi untuk roda depan dan roda belakang dilakukan dengan beberapa cara, salah satunya yaitu dengan membandingkan masing masing kedalam sebuah tabel agar dapat dianalisis dengan cepat. Untuk salah satu grafik dengan contoh pembagian porsi traksi pada ban depan $45 \%$ dan ban belakang 55\% dapat dilihat pada gambar 8 .

Pada gambar 8 terlihat batas adhesi sangat jauh dari traksi yang dihasilkan kendaraan dengan kisaran nilai terendah pada jalan raya yang basah dengan sudut tanjak sebes ar 30\%, tetapi pada posisigigi 1 dengan traksi yang dihasilkan sekitar 3000 $\mathrm{N}$ pada porsi $45 \%$ untuk roda depan sedangkan pada porsi 55\% untuk roda belakang menghasilkan traksi sekitar 3800 $\mathrm{N}$, kendaraan hanya mampu melewati gradien sebesar $15 \%$ 
tetapi untukgradient $0 \%$ dari mulai gigi 1 sampai gigi 4 dapat melaju dengan lancar tanpa terganggu adanya slip.

Dari tabel 5 dapat dilihat bahwa penggunaan tingkat gigi tidak melewati Batas adhesi pada mode 4WD untuk tidak melewati batas adhesi berupa jenis jalanan, kondisi jalan yaitu basah dan kering serta gradien jalan dari mulai $0 \%$ hingga $15 \%$. Dapat dilihat bahwa pada variasi pembagian traksi dengan $45 \%$ menuju roda depan dan $55 \%$ menuju roda belakang hampir semua Batas adhesi dapat dilewati oleh kendaraan tersebut tetapi pada saat kendaraan melewati jalanan lumpur yang basah dengan gradien 15\% maka kendaraan diam tidak bergerak karena traksi yang dihasilkan lebih kecil daripada hambatan ketika menanjak untuk melewatinya. Pada variasi pembagian traksi antara roda depan 50\% dan roda belakang 50\% semua batas adhesi dadapat dilewati dengan baik tetapi hambatan tanjak kendaraan tersebut hanya dengan menggunakan tingkat gigi 1 pada jalan raya tetapi ketika jalanan lumpur kendaraan tersebut diam karena tidak mampu melawan hambatan gradien.

Untuk mengetahui kendaraan itu harus menggunakan metode penyeleksian sistem penggerak, supaya lebih mudah maka dibuat tabel seperti pada tabel 6 .
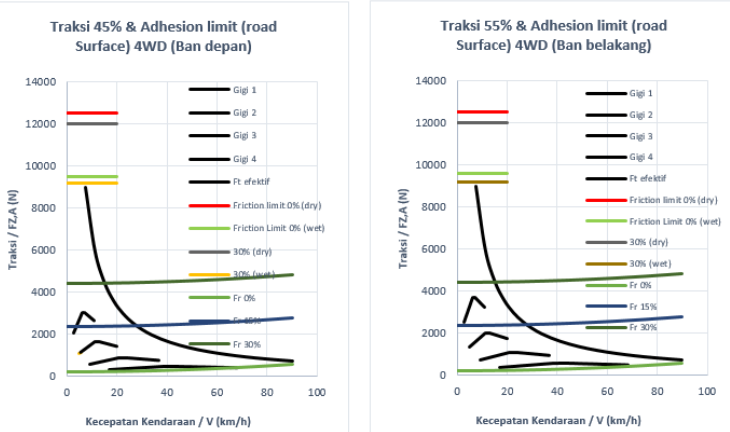

Gambar 8 . Mode 4WD dengan pembagian porsi torsi $45 \%$ roda depan dan $55 \%$ untuk roda belakang.

Tabel 5 .

Penggunaan tingkat transmisi untuk melawan hambat an tanjak dan tidak melebihi bat as adhesi pada mode $4 \mathrm{WD}$

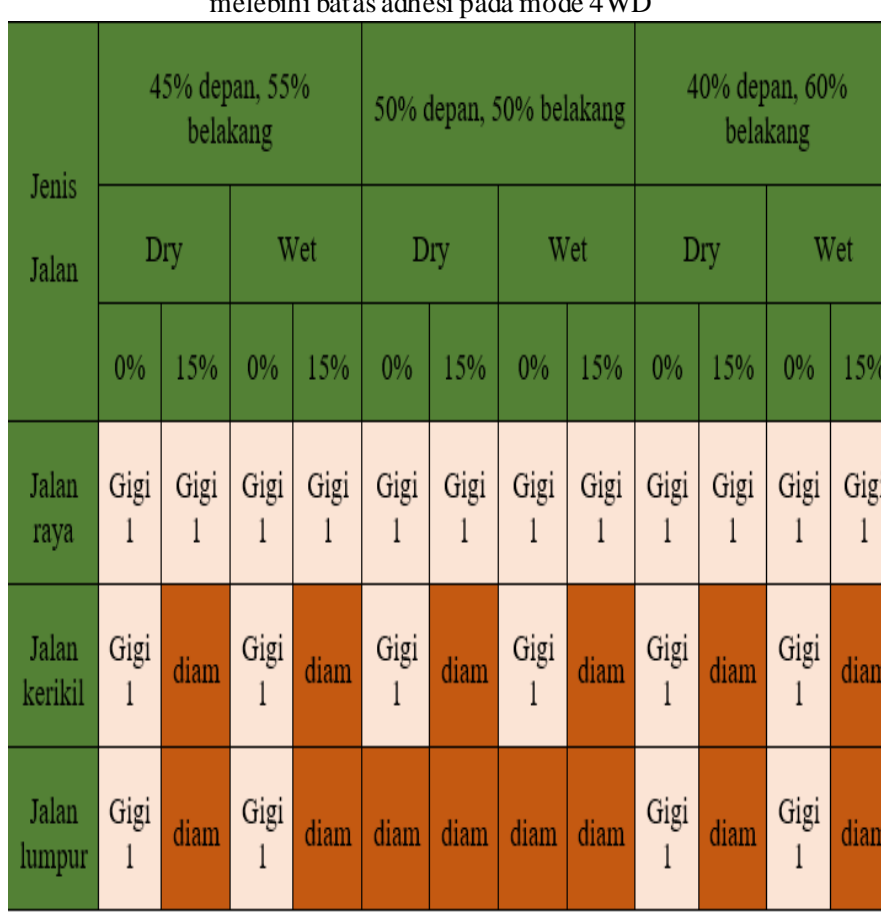

\section{H. Pemilihan RWD, FWD, dan $4 W D$}

Tabel 6.

Penyeleksian penggerak untuk kendaraan

\begin{tabular}{|c|c|c|c|c|c|c|c|}
\hline \multirow{2}{*}{ No } & \multirow{2}{*}{ Kategori } & \multirow{2}{*}{ FWD } & \multirow{2}{*}{ RWD } & \multirow{2}{*}{$4 \mathrm{WD}$} & \multicolumn{3}{|c|}{ Nilai } \\
\hline & & & & & FWD & RWD & $4 \mathrm{WD}$ \\
\hline 1 & Harga & Murah & Mahal & Mahal & 3 & 2 & 1 \\
\hline 2 & Kecepatan & $63 \mathrm{~km} / \mathrm{h}$ & $63 \mathrm{~km} / \mathrm{h}$ & $30 \mathrm{~km} / \mathrm{h}$ & 3 & 3 & 1 \\
\hline 3 & Percepatan & $3 \mathrm{~m} / \mathrm{s}^{2}$ & $3 \mathrm{~m} / \mathrm{s}^{2}$ & $1.3 \mathrm{~m} / \mathrm{s}^{2}$ & 2 & 3 & 1 \\
\hline 4 & Gradability & $47 \%$ & $47 \%$ & $20 \%$ & 2 & 3 & 1 \\
\hline 5 & Slip & mudah & biasa & bagus & 1 & 2 & 3 \\
\hline 6 & On road & ya & ya & $\mathrm{Ya}$ & 3 & 3 & 2 \\
\hline 7 & Off road & tidak & ya & уа & 1 & 2 & 3 \\
\hline 8 & Massa total & $1300 \mathrm{~kg}$ & $1500 \mathrm{~kg}$ & $1500 \mathrm{~kg}$ & 1 & 3 & 3 \\
\hline & & Jumlah & & & 16 & 21 & 15 \\
\hline
\end{tabular}

Pada tabel 6 untuk segi harga maka FWD lebih unggul dibandingkan dengan RWD karena secara kontruksi gearbox yang dekat dengan gardan depan sangat dekat karena posisi mesin didepan. Dari segi penggunaan untuk jalan pedesaan maka RWD lebih unggul daripada FWD karena tidak menimbulkan banyak slip. Dari segi kecepatan dan percepatan RWD dan FWD mempunyai nilai yang sama. Untuk mass a total kendaraan RWD lebih baik daripada FWD karena distribusi beban ketika kendaraan melaju akan lebih merata jika menggunakan penggerak roda belakang. Untuk 4WD maka dimasukan sebagai penggerak semua roda agar mengurangi slip pada roda. Jadi kesimpulan penggunaan penggerak mobil WAPRODES yaitu menggunakan RWD dan 4WD.

\section{KESIMPULAN}

Kesimpulan yang didapat dari hasil perancangan dan analisis yaitu sebagai berikut:

1. Saat pemilihan mesin power minimal yang harus dimiliki mesin kendaraan adalah 14.5 KW. Maka hasil pembobotan didapatkan mesin yang cocok yaitu RATNA DDi $2700 \mathrm{~F}$ dengan power $20 \mathrm{KW}$ serta torsi 88 N.m

2. Pada Powertrain kendaraan WAPRODES telah didapatkan rasio gigi tiap tingkat kecepatan, untuk rasio tingkat gigi pertama mempunyai nilai yaitu 5.66, sedangkan rasio tingkat gigi kedua mempunyai nilai yaitu 3.057, lalu rasio tingkat gigi ketiga mempunyai nilai yaitu 1.650, dan rasio tingkat gigi keempat mempunyai nilai yaitu 0.89 .

3. Sistem powertrain kendaraan WAPRODES dapat menghasilkan traksi maksimum pada gigi tingkat ke-1 dengan nilai $7649 \mathrm{~N}$, untuk gigi tingkat ke-2 dengan nilai $4199 \mathrm{~N}$, lalu gigi tingkat ke-3 dengan nilai $2361 \mathrm{~N}$, dan gigi tingkat ke-4 dengan nilai $1327 \mathrm{~N}$.

4. Indikator Kemampuan menanjak menunjukkan sudut tanjak maksimum yang dapat dicapai sebuah kendaraan setelah didesain. Untuk kondisi permukaan jalan raya, sudut tanjak maksimum yang dapat dicapai yaitu $54 \%$. 
Pada kondisi permukaan jalan jelek (tanah/berkerikil) sudut tanjak maksimum kendaraan adalah $37 \%$. Untuk kendaraan yang melaju diatas permukaan pasir atau lumpur sudut tanjak maksimum kendaraan adalah $27 \%$.

5. Indikator kemampuan akselerasi menunjukkan percepatan maksimum kendaraan yang dapat dicapai setelah didesain. Untuk kondisi permukaan jalan raya mempunyai nilai $3 \mathrm{~m} / \mathrm{s}^{2}$.

6. Sistem penggerak $4 \mathrm{WD}$ dengan desain terbaik yaitu dengan traksi $45 \%$ untuk roda depan dan $55 \%$ untuk roda belakang dan untuk $2 \mathrm{WD}$ menggunakan RWD.

\section{DAFTAR PUSTAKA}

[1] $\mathrm{Cv}$ Bengkel Murni. "Mobil Penggiling Padi". < http://www.cvbengkelmurni.com/detail/penggilingan_padi_mobil_se lep_padi_jalan-be2.htm>.16 Mei 2017.
[2] G.A. Necati. 1990. "Measurement and Test Techniques," in W.-H Hucho, Ed., Aerodynamics of Road Vehicles. London: But terworths Heinemann, 1990.

[3] J.J. Taborek, "Mechanics of Vehicles," Machine Design, May 30Dec. 26. 1957.

[4] J.G. Giles, Gears and Transmissions, Automotive Technology Series, vol. 4, London: Butterworths, 1969

[5] J.R. Ellis, Vehicle Dynamics, London: Mechanical Engineering Publication, 1994.

[6] R.R. Guntur and J.Y. Wong, “Application of the Parameter Plane Methode to the Analysis of Directional Stability of TractorSemitrailers," Transaction of the ASME, journal of Dynamic System, Measurement and Control, vol. 100, no. 1, March 1978

[7] D.J. Bickerstaff and G. Hart ley, "Light Truck Tire Traction Properties and Their Effect on Braking Performance," SAE Transactions, vol. 83, paper 741137, 1974.

[8] Sunggono, Muhammad Sukma Wirayudha. "Perancangan Dan Analisa Karakteristik Traksi Sistem Powertrain Mobil Multiguna Pedesaan”. Teknik Mesin ITS Surabaya. 2017. 